\title{
Vicious circle behavior as a function of delay of punishment'
}

\author{
R. Chris Martin, WENNER-GREN AERONAUTICAL RESEARCH LABORATORY, UNIVERSTTY OF KENTUCKY \\ Kenneth B. Melvin, UNIVERSITY OF ALABAMA
}

\begin{abstract}
Abstraet
Rats were given shock-escape training in a $4 \mathrm{ft}$ runway, then divided into 3 groups of 10 Ss each. During extinction one group received $1 \mathrm{ft}$ of shock immediately after leaving the start box, a second group was shocked in the last $1 \mathrm{ft}$ section of the alley, and a control group was never shocked. The immediate-shock group was found to be more resistant to extinction, followed successively by the delayed-shock group and the no-shock group.
\end{abstract}

\section{Problem}

"Vicious circle" behavior refers to the behavioral paradox of strengthened resistance to extinction of escape and avoidance responses as an effect of punishment (Mowrer, 1960). The occurrence of this phenomenon in an instrumental escape situation has been found to be an increasing function of (a) the length of the electrified grid during extinction (Brown et al, 1964) (b) the percentage of punished trials (Melvin, in press) and (c) up to a certain limit, the intensity of punishment (Gwinn, 1949; Martin, 1964). While the study by Brown, et al established certain necessary conditions for the appearance of the phenomenon, no effort.was made to separate the effects of amount and delay of punishment. In the present study, delay of punishment was varied, while amount of punishment was held constant for the punished groups.

In situations where punishment results in response suppression, the available evidence indicates that delayed punishment is less effective than immediate punishment (cf. Kimble, 1961). Kamin (1959) found suppression of the resistance to extinction of an avoidance response as an overall effect of punishment, with less suppression occurring at greater amounts of delay. Thus, in the vicious circle situation, where punishment serves to strengthen resistance to extinction, it was expected that delayed punishment would be less facilitating than immediate punishment.

\section{Method}

The Ss were 30 male albino rats, Wistar strain, about 140 days old. For 14 days prior to the experiment, they were maintained on a restricted diet of 14 gm of chow per day with water available ad lib. At the beginning of training, Ss were approximately $23 \mathrm{hr}$. hungry.

The apparatus was a straight runway, 6 in wide, 72 in long, and 10 in high, inside. Two guillotine doors 12 in from each end divided the runway into a start box, $4 \mathrm{ft}$ alley, and goal box. The floor of the start box and alley was a grid of $1 / 8$ in stainless steel rods imbedded in plastic at $3 / 4$ in interval; the goal-box floor was wooden. Hardware cloth covered the apparatus and was hinged for doors over the start box and goal box. Raising the start-box door turned on the shock and an electric clock; the clock stopped and S passed a photocell unit at the junction of the alley with the goal box. Shock intensity was controlled by means of a variable voltage autotransformer and delivered through a series resistor of $10.000 \mathrm{ohms}$.

Shock-escape training consisted of 4 pre-training trials and 12 training trials. On pre-training trials, $\mathrm{S}$ was placed on the charged grid $(60 \mathrm{v})$ at a distance of $2 \mathrm{ft}$ from the goal box, into which he escaped. On training trials, $\mathrm{S}$ was placed in the start box and 3 sec. later the door was raised and the grid energized $(65 \mathrm{v})$. When the rat entered the goal box, the door was lowered to prevent retracing and he remained there for $30 \mathrm{sec}$. The intertrial interval was about $1 \mathrm{~min}$.

Immediately following training, $S$ received further trials under one of these conditions: (a) shock (65 v) was present only on the first 8 in of grid immediately in front of the start box (b) shock (65 v) was present only on the 1 ast 8 in of grid immediately in front of the goal box and 40 in from the start box or (c) shock was no longer present in any part of the apparatus. Note that shock was never present in the start box under any condition. Ten Ss were randomly assigned to each condition. Sixty such "extinction" trials were given, provided the rat continued to run. If $S$ failed to reach the goal box within 60 sec., testing ceased and arbitrary scores of $60 \mathrm{sec}$. were recorded.

\section{Results}

Figure 1 shows the mean number of trials to extinction for the three groups. It is clear from this figure that the immediate-shock group was most resistant to extinction, followed successively by the delayed-shock group and the no-shock group. Analysis of variance revealed that these differences were reliable $(F=12.67$; $\mathrm{df}=2 / 27 ; \mathrm{p}<.001$ ).

Mean running speeds over blocks of three trials are presented in Fig. 2. From this it is evident that the immediate-shock group ran faster than the other two groups, and, in fact, showed little tendency to extinguish during the first 30 trials. A Lindquist Type I analysis of variance indicated significant differences for groups $(F=19.51 ; d f=2 / 27 ; p<.001)$, days $(F=5.67$; $\mathrm{df}=9 / 243 ; \mathrm{p}<.001)$, but not for the interaction of groups $\mathrm{x}$ days $(\mathrm{F}=1.37 ; \mathrm{df}=18 / 243 ;(.05<\mathrm{p}<.10)$.

\section{Diseussion}

The results indicate that punishment facilitated resistance to extinction, and furthermore, the shorter the 


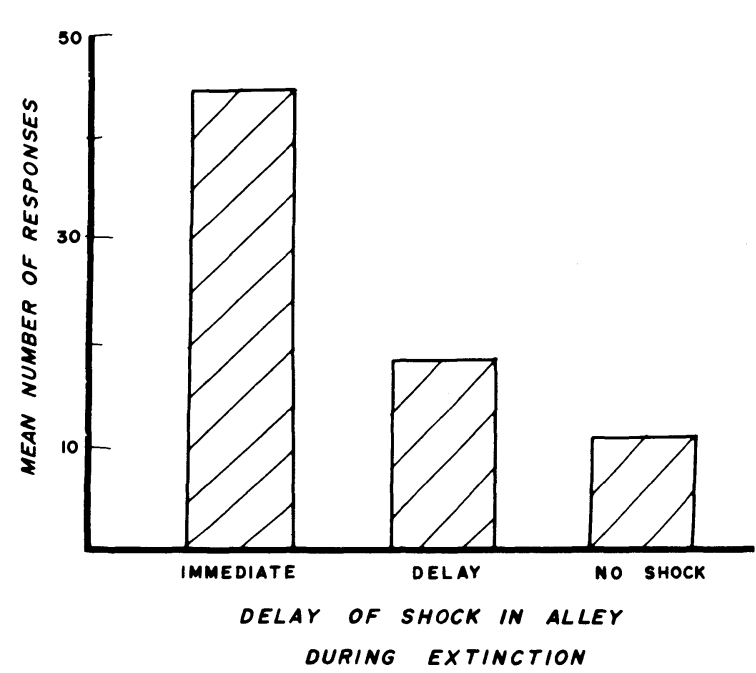

Fig. 1. Mean number of responses to extinction.

delay of punishment, the stronger was performance during extinction. These seemingly paradoxical results are compatible with previous findings reported by Gwinn (1949), Brown et al (1964), and Melvin (in press). It should be noted that two investigators have not found punishment to strengthen the resistance to extinction of an escape response (Moyer, 1957; Seward \& Raskin, 1960).

Our interpretation of the results is based on Mowrer's (1960) explanation of this self-punishment behavior. During extinction the rat runs due to fear, running results in shock which elicits the conditioned running response and maintains fear. Furthermore, the shock just prior to the goal box elicits fear which generalizes back down the homogeneous alley. The generalization gradient tells us that more fear will be present in the start box with immediate shock than delayed shock. The greater the fear in the start box the higher the probability that $\mathrm{S}$ will perform the learned response and thus punish himself. Further evidence supporting the above analysis of vicious circle behavior has been provided by Melvin (in press).

While the experimental procedure involved delay of punishment, it also involved delay of reinforcement, i. e., shock termination. Brown et al (1964) have extended Mowrer's explanation by noting that running is reinforced, for punished groups by pain reduction as well as fear reduction. Part of the superior performance of the immediate-shock group may be due to the earlier shock termination and thus the more immediate reinforcement of the running response.

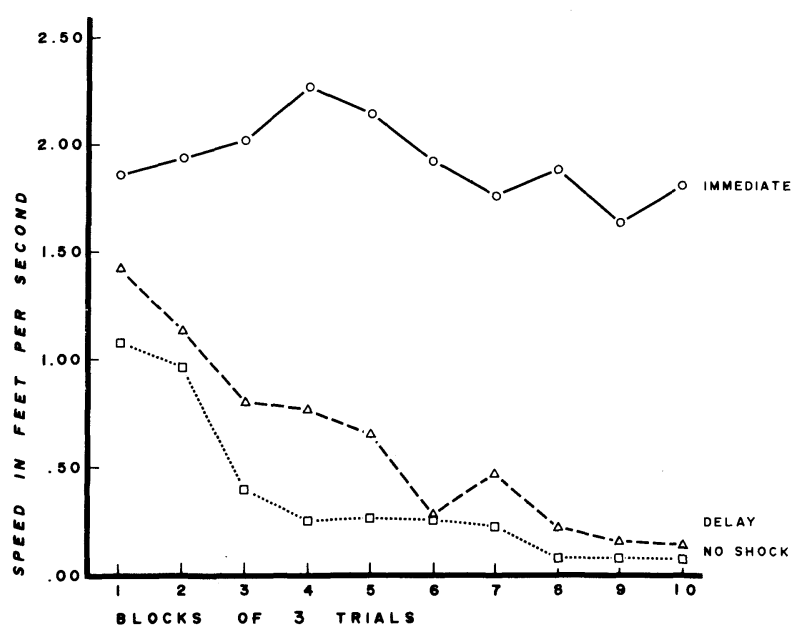

Fig. 2. Mean speed in feet per second for the three groups ơver blocks of three trials during extinction.

These results relate to those of Brown et al (1964) which showed that $6 \mathrm{ft}$ of punishing shock leads to greater resistance to extinction than $2 \mathrm{ft}$ of delayed shock. Their finding may result not from the difference in the length of the electrified grid but rather that the $2 \mathrm{ft}$ shock was delayed whereas the $6 \mathrm{ft}$ shock began immediately. However, it seems likely that the longer grid shock is experienced, the greater will be resistance to extinction, with a fixed amount of delay. A study exploring this possibility is now. in progress.

\section{References}

BROWN, J. S., MARTIN, R. C., \& MORROW, M. W. Self-punitive behavior in the rat: Facilitative effects of punishment on resistance to extinction. J.comp. physiol. Psychol., 1964, 57, 127-133. GWINN, G. T. The effects of punishment on acts motivated by fear. J. exp. Psychol., 1949, 39, 260-269.

KAMIN, L. J. The delay of punishment gradient. J. comp. physiol. Psychol., 1959, 52, 434-437.

KIMBLE, G. A. Hilgard and Marquis' conditioning and learning. New York: Appletion-Century-Crofts, 1961.

MARTIN, R. C. Vicious circle behavior in the rat as a function of the intensity of punishment. Paper read at S. E. P. A. meeting, Gatlinburg, April, 1964.

MELVIN, K. B. Escape learning and "vicious circle" behavior as a function of percentage of reinforcement. J.comp. physiol. Psychol., in press.

MOWRER, O. H. Learning theory and behavior. New York: Wiley, 1960.

MOYER, K. E. The effects of shock on anxiety-motivated behavior in the rat. J. genet. Psychol., 1957, 91, 197-203.

SEWARD, J. P., \& RASKIN, D. C. The role of fear in aversive behavior. J. comp. physiol. Psychol., 1960, 53, 328-335.

\section{Note}

1. Supported by the Veterans Administration Hospital, Augusta, Georgia, 